\title{
Erratum: Type of shelter and first description of the echolocation call of disk-winged bat (Thyroptera devivoi)
}

In the article "Type of shelter and first description of the echolocation call of disk-winged bat (Thyroptera devivoi)", with the DOI code number: http://dx.doi.org/10.1590/1676-0611-BN-2019-0821, published at Biota Neotropica 20(2): e20190821, on page 4:

Where it was written:

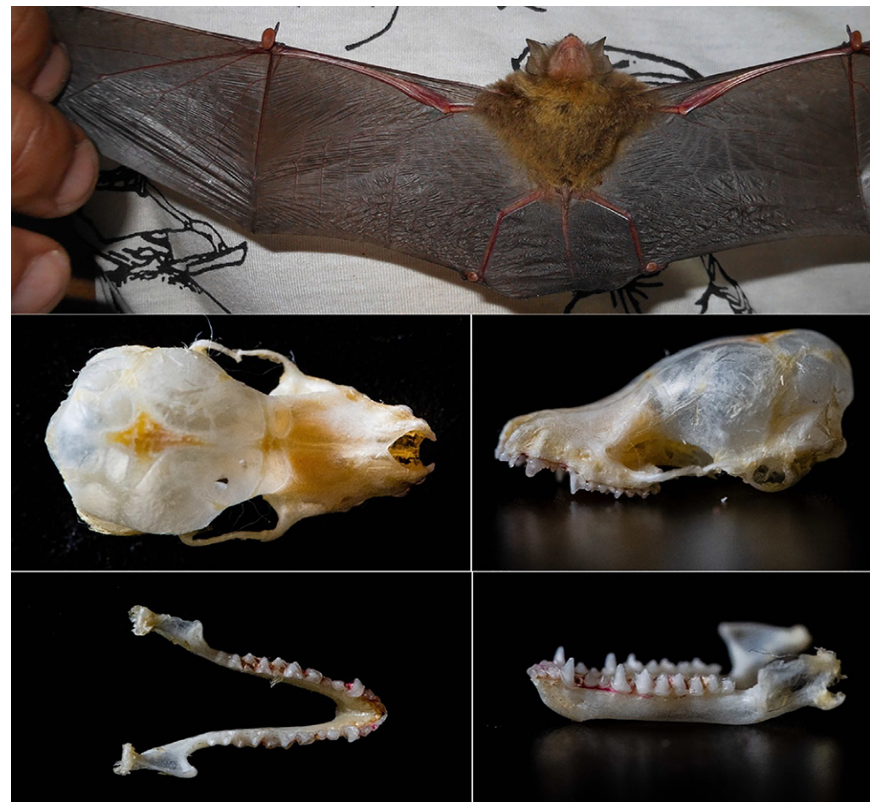

Should read:

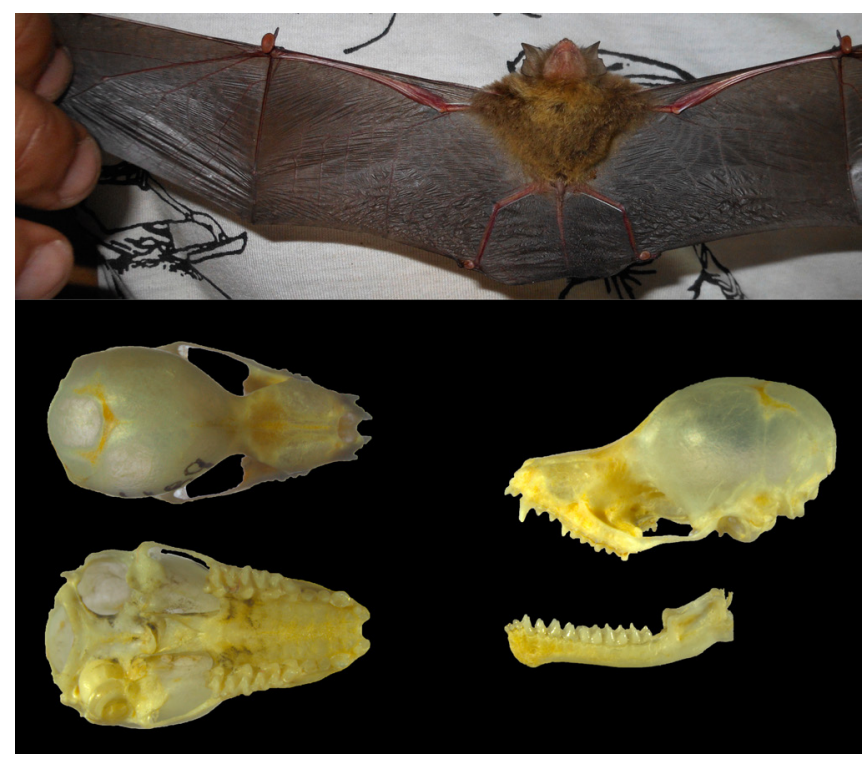

The authors would like to thank the authors of the article:

MORALES-MARTÍNEZ, D. M., RODRÍGUEZ-POSADA, M. E. ACOSTA-MORALES, S. G. \& SALDARRIAGA-GÓMEZ, A. M. 2021. First confirmed record of the LaVal's Disk-winged Bat, Thyroptera lavali Pine, 1993 (Chiroptera, Thyropteridae), from Colombia. Check list 17(2):471-478 for finding and describing the error. 